\title{
FAME Storage Time in an Optimized Natural Antioxidant Mixture
}

\author{
Rodolfo Lopes Coppo, Dionísio Borsato, Jaqueline Laís Pereira, \\ and Hágata Cremasco da Silva
}

Fuels Analyses and Research Laboratory (LPAC), Chemistry Department, State University of Londrina, P.O. Box 6001, 86051-990 Londrina, PR, Brazil

Correspondence should be addressed to Dionísio Borsato; dborsato@uel.br

Received 23 August 2012; Revised 16 October 2012; Accepted 1 November 2012

Academic Editor: Kanit Krisnangkura

Copyright (C) 2013 Rodolfo Lopes Coppo et al. This is an open access article distributed under the Creative Commons Attribution License, which permits unrestricted use, distribution, and reproduction in any medium, provided the original work is properly cited.

The study of B100 biodiesel oxidation stability, and its conservation, is extremely important to control its quality, especially regarding storage. Many spices have shown antioxidant effect and are the targets of study. Knowing the oxidation process in greater detail allows a reliable storage period to be stipulated for the biodiesel without its degradation until the time of use. Results have shown that according to the accelerated stove method, the optimal mixture, composed of $100 \%$ of oregano extract, can confer a 535-day shelf life to biodiesel without evident oxidation. According to the results obtained by the Rancimat method, the ideal mixture consists of $100 \%$ rosemary, resulting in 483 days of storage. The application of the process variable showed that the accelerated stove method was more suitable to determine oxidative stability of biodiesel.

\section{Introduction}

For many decades, fossil fuels have supplied the energy demand but it is known that these fuels release carbon dioxide gas, the main cause of the greenhouse effect, and sulphur oxides, associated to the acid rain phenomenon. These negative contributions to the environment have triggered the search for sources of clean and renewable energy and the use of biofuels has presented a viable alternative to solve these problems [1]. The use of biomass, represented mainly by vegetable oils, is a good strategy both in economic terms and environmental preservation [2].

In this context, biodiesel can be highlighted. It is defined as mono-alkyl ester from fatty acids produced by the reaction of vegetable oils or animal fat with alcohol, usually methanol, in the presence of a catalyst, normally a strong base such as sodium or potassium hydroxide, or even an acid, and this reaction is known as transesterification $[3,4]$.

The high compatibility of biodiesel with petroleum diesel characterizes it as an good alternative capable of supplying most of the existing diesel fleet without great adaptations. It is also biodegradable and renewable, has a lubricant capacity in the pure form, and is competitive with diesel in terms of fuel properties [1].
However, unlike fossil fuels that are relatively inert and maintain their essential characteristics with little alteration during storage, biodiesel degrades with time and can be altered due to the action of air, light, temperature, and moisture. Contact with contaminants, both inorganic and microbial nature, can also tend to introduce variations in product quality, and oxidation resulting from its exposure to atmospheric air is one of the main degradation problems to which biodiesel is subject [4].

Some oilseeds produce oils with undesirable chemical characteristics that are incorporated into the biodiesel during the production process. One example is soybean, which originates oils with a high degree of unsaturations, favoring biodiesel oxidation reactions, which causes storage difficulties [1]. Stability to oxidation is therefore a very important parameter to control the biodiesel quality $[3,5]$.

In order to inhibit or delay oxidation in oils, fats, and fatty foods, phenolic chemical compounds are used, known as synthetic antioxidants and/or stabilizers [6]. Antioxidants occur naturally in vegetable oils and the most common are the tocopherols. However, some plant oil production processes include a distillation step to purify the triglycerides. The biodiesel obtained from these oils normally has little or no natural antioxidants so they become less stable and 
therefore antioxidants need to be applied to increase the biofuel stability and extend its properties for a longer period [7].

A new alternative to delay the biodiesel oxidative degradation process may be the use of natural antioxidants present in spices, bearing in mind that they do not damage the environment and are easily obtained [8]. According to some studies, rosemary (Rosmarinus officinalis L.) and sage (Salvia officinalis L.) are the spices with the greatest antioxidant potential $[8,9]$. The antioxidant activity of carnosol and carnosic acid, found in rosemary, was validated in an emulsion containing methyl linoleate [10]. According to Nakatani and Inatani (1984), the addition of natural antioxidants such as carnosol and carnosic acid, at a $0.01 \%$ concentration, in a linoleic acid emulsion, have activity levels similar to those of the synthetic antioxidants BHA (butyl hydroxy anisole) and BHT (butyl hydroxy toluene) added in the same concentration [11].

Five different phenolic compounds were isolated from oregano (Origanum vulgare L.); all presented antioxidant activity and one of them was identified as rosmarinic acid [12]. Furthermore, the study carried out by Bragagnolo and Mariutti [13] reported several other phenolic compounds that were isolated from oregano, including luteolin, $\mathrm{p}$ coumaric acid, carvacrol, thymol, p-cimen, and campherol. These findings demonstrate a great possibility of using these spices as good antioxidants and possible substitutes for the synthetic antioxidants, especially in mixtures consisting of carbon compounds with unsaturations as substrate.

Developing a product involving more than one component requires some particular forms of mixture experiments [14]. Experimental plans are the base of efficient and effective knowledge, founded on statistics, for data treatment. Many studies that use designs for experiments with mixture have followed the models by Scheffé that allow exploration of all experimental region [15-17] and a more complete reference for problems with mixtures is Cornell and Deng [18].

In experiments with mixture it is not possible to vary one component while the others maintain constant. As soon as the proportion of one component is altered, the others are also altered, because the sum of all the components is $100 \%$ [17].

Optimization methods have been applied in the last 20 years in various ways in the fields of engineering, chemical processes industry, heating, and management for cost reduction [19]. The optimal formulation of a product is not only strictly a technological nor a commercial one. Generally, both areas offer restrictions that contribute to determine which of the formulations are possible [20].

The objective of the present study was to determine an optimized natural antioxidant formulation, in B100 biodiesel, by the simplex-centroid design, in order to stipulate the commercial Storage Time of these mixtures at room temperature. Thus, the application of process variable provided a comparison between two methods used for determining biodiesel oxidative stability: Rancimat and Acelerated Stove.

\section{Experimental Section}

2.1. Biodiesel. The B100 biodiesel used was obtained by soybean oil transterification by methyl pathway using sodium methoxide as catalyst. $1000 \mathrm{~mL}$ of soybean oil were mixed with methanol and sodium methoxide $(8 \mathrm{~g} / 500 \mathrm{~mL}$ alcohol), under slow agitation. The mixture was submitted to reflux at $60^{\circ} \mathrm{C}$. Phases were separated in a specific funnel. The obtained esters were washed with water, at $80^{\circ} \mathrm{C}$, and $1.5 \%$ of acetic acid, until neutral $\mathrm{pH}$. The biodiesel was dehumidified in stove at $140^{\circ} \mathrm{C}$ for two hours [21].

2.2. Chromatographic Analysis. A Shimadzu gas chromatograph was used, model GC-17A, with a flame ionization detector, DB1 column (J\&W SCIENTIFIC)-100\% polymethylsiloxane $30 \mathrm{~m}$ long $\times 0.25 \mathrm{~mm}$ internal diameter $\times$ $0.25 \mu \mathrm{m}$ film thickness. The on-column injector had the same temperature as the column ramp. The column heating ramp, first at $50^{\circ} \mathrm{C}$, remained for $2 \mathrm{~min}$, heated at a rate of $10^{\circ} \mathrm{C} \mathrm{min}{ }^{-1}$ until $180^{\circ} \mathrm{C}$ remained for $2 \mathrm{~min}$ and, finally, heated at the rate of $15^{\circ} \mathrm{C} \mathrm{min}^{-1}$ until $340^{\circ} \mathrm{C}$ and remained for $22 \mathrm{~min}$. The drag gas flow, $\mathrm{N}_{2}$, was $1.5 \mathrm{~mL} \mathrm{~min}^{-1}$ and the injection volume was $2.0 \mu \mathrm{L}$. The data were acquired and treated by the Software CLASS-CR10.

2.3. Antioxidants. Alcoholic extracts were used from three natural antioxidants: rosemary (Rosmarinus sp), oregano (Origanum vulgare sp), and basil(Ocimun sp). The three herbs were acquired in the dried form. Ten grams of each sample were weighed, separately, and $250 \mathrm{~mL}$ of absolute ethanol added; this mixture was left to rest for 24 hours and the extracts were filtered. The filtrates were evaporated, using a hot plate, to approximately $50 \mathrm{~mL}$, at $60^{\circ} \mathrm{C}$, and transferred to volumetric flasks and their volumes completed to $50 \mathrm{~mL}$ with absolute ethanol. The alcoholic extract concentration used of each antioxidant in B100 biodiesel was $0.7 \%(\mathrm{v} / \mathrm{v})$. The antioxidants proportions of each treatment were established by the mixture design and incorporated directly into the substrate before assessing its oxidative stability [22]. The same concentration of alcohol was added to control sample.

2.4. Antioxidant Assessment by Infrared Spectroscopy. The spectra of the three antioxidant alcoholic extracts were recorded in the equipment Thermo Scientific Nicolet iS10 FTIR, in the wavelength range of $675-4000 \mathrm{~cm}^{-1}$.

2.5. Oxidative Stability Assessment Determined by the Accelerated Stove Method. The biodiesel samples containing the proportions of antioxidant established by the simplex-centroid design, and the control samples, were taken to stoves at three temperatures: 40,55 , and $70^{\circ} \mathrm{C}$. The peroxide value (PV), expressed in meq kg ${ }^{-1}$ sample, was monitored with $0.1 \mathrm{~N}$ sodium tiosulphate, by the AOCS Cd 8-53 method, until the maximum PV of each essay was reached [23]. With these data, a curve of the peroxide value versus analysis time, in days, was generated. The inflection point of the curve, represented by the second derivative of the experimental data, was calculated by CurTiPot, Derive, and Curve Expert Freewares and its 
value indicates the Induction Period (IP), that corresponded to the beginning of propagation reactions [24].

2.6. Oxidative Stability Assessment Determined by the Rancimat Method. Samples of $3 \mathrm{~g}$ biodiesel containing the antioxidants and the control samples were taken to accelerated heating at $110,115,120$, and $130^{\circ} \mathrm{C}$, with a $10 \mathrm{~L} \mathrm{~h}^{-1}$ insufflation rate, to determine the Induction Period. The test was carried out using the Rancimat 873 following the official standard for determining the oxidative stability by the accelerated test [25].

2.7. Conformity Analyses. B100 Biodiesel specific mass was determined according to ASTM D4052 method [26], flash point according to ASTM D93 method [27], acidity index by ASTM D664 method [28]. Glycerin, mono-, di-, and triglycerides assay by ASTM 6584 method [29], and alcohol and esters assay by EN 14103 [30].

2.8. Mixture Experimental Design [31]. The simplex-centroid design was applied with two replications on the central point and one replication on the control sample. The number of mixture combinations was $2^{q}-1$, where $q$ represents the number of components with a sum equal to one or $100 \%$ [32]. The other combinations were carried out in a single sample.

2.9. Statistical Analysis. The regression coefficients were estimated using the software Statistica v.9.0 [31].

\subsection{Mathematical Model. The function used was}

$$
Y(x)=\sum_{1 \leq i \leq q} \gamma_{i}^{\circ} x_{i}+\sum_{1 \leq i \leq j \leq q} \gamma_{i j}^{\circ} x_{i} x_{j}+\gamma_{123}^{\circ} x_{1} x_{2} x_{3},
$$

where $Y$ is the response function of the experimental data, $x_{1}, x_{2}$, and $x_{3}$ the independent variables that correspond to the percentage of rosemary, oregano, and basil extracts in the mixture, respectively, and $\gamma^{0}$ are the estimated parameters [33].

2.11. Combined Mathematical Model. The model was fitted for the combination $\left(2^{q}-1\right) \times 2^{n}$, where $n$ represents a number of discrete variables in the process, represented in (2) by $z$ that was codified to $z=+1$, for the data obtained by the accelerated stove method, and $z=-1$ for the data obtained by the Rancimat test. The regression coefficients of the model were obtained by the least squares method, by the matrical equation $\gamma=\left(A A^{\prime}\right)^{-1} A^{\prime} B$, where $A$ is the design matrix including the process variable, $A^{\prime}$ the transposed matrix, and $B$ is the response vetor

$$
\begin{aligned}
Y(x, z)= & \sum_{1 \leq i \leq q} \gamma_{i}^{\circ} x_{i}+\sum_{1 \leq i \leq q} \gamma_{i}^{1} x_{i} z \\
& +\sum_{1 \leq i \leq j \leq q} \gamma_{i j}^{\circ} x_{i} x_{j}+\sum_{1 \leq i \leq j \leq q} \gamma_{i j}^{1} x_{i} x_{j} z \\
& +\gamma_{123}^{\circ} x_{1} x_{2} x_{3}+\gamma_{123}^{1} x_{1} x_{2} x_{3} z,
\end{aligned}
$$

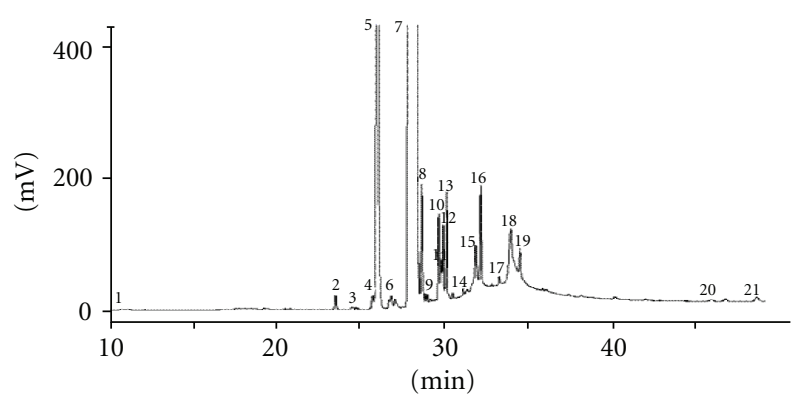

FIGURE 1: B100 Biodiesel chromatographic profile.

where $\gamma^{\circ}$ represents the estimated parameters for the terms without the process variable and $\gamma^{1}$ the parameters estimated for the terms containing the process variable [18].

\section{Results and Discussion}

The study of biodiesel quality standards must establish contents limit for contaminants that do not harm the quality of the burn emissions, performance, engine integrity, and safety in transport and handling. Possible degradations of the product during the storage process should be taken into consideration [34].

Table 1 shows the main conformity parameters of the B100 biodiesel used. The Induction Period and mono- and diglycerides were the parameters that did not meet the specifications established by resolution 14 [35].

The ester content in biodiesel is a parameter provided by EN 14103, with 96.5\% (in mass) minimum ester percentage required, to be determined by the EN ISO 14103 [30] chromatographic method [34]. The analysis in Table 1 shows that the ester content was higher than the minimum value required.

The chromatographic analysis (Figure 1) depicted that the biodiesel consisted basically of methyl esters with chemical composition variation from C14:0 to C22:0.

Table 2 summarizes the components quantified in B100 biodiesel.

All esters cited in Table 2 accounted for $98.15 \%$ of the substances present in the B100 biodiesel, meeting the specifications of European Union which establishes that the content of free fatty acids, alcohol, glycerin, and water should be minimum so that the purity of the biodiesel must be greater than $96.5 \%$ [36]. These results are in line with the percentages of the fatty acid ester distribution of soybean oil obtained by Borsato et al. [37] that were 19.8\% for C16 and approximately $73.8 \%$ for $\mathrm{C} 18$.

Residual glycerin determination works as a parameter to assess the efficiency of the biodiesel purification process. High glycerin concentrations in biodiesel cause storage problems because when biodiesel is mixed with petroleum diesel the glycerin separates in the storage tanks. Deposit formation, blocking of the engine injector nozzles and aldehyde emissions are also related to high glycerin concentration in biodiesel [34]. 
TABLE 1: Conformity parameters of B100 biodiesel from soybean.

\begin{tabular}{|c|c|c|c|c|}
\hline Characteristic & Method & Unity & Limit & Result \\
\hline Specific mass at $20^{\circ} \mathrm{C}$ & ASTM D4052 & $\mathrm{Kg} \mathrm{m}^{-3}$ & $850-900$ & 890 \\
\hline Flash point & ASTM D93 & ${ }^{\circ} \mathrm{C}$ & Min. 100 & 150.4 \\
\hline Acidity & ASTM D664 & $\mathrm{mg} \mathrm{KOH} \mathrm{g}^{-1}$ & Max. 0.50 & 0.19 \\
\hline Free glycerin & ASTM D 6584 & $\%$ weight & Max. 0.02 & 0.013 \\
\hline Total glycerin & ASTM D 6584 & \% weight & Max. 0.25 & 0.160 \\
\hline Monoglycerides & ASTM D 6584 & \% weight & 0.80 & 1.490 \\
\hline Diglycerides & ASTM D 6584 & $\%$ weight & 0.20 & 0.251 \\
\hline Triglycerides & ASTM D 6584 & $\%$ weight & 0.20 & N.D. ${ }^{a}$ \\
\hline Methanol & EN 14110 & $\%$ weight & Max. 0.20 & N.D. ${ }^{a}$ \\
\hline Esters content & EN 14103 & $\%$ weight & Min. 96.5 & 98.15 \\
\hline Induction period at $110^{\circ} \mathrm{C}$ & EN 14112 & Hours & Min. 6 & 3.56 \\
\hline
\end{tabular}

${ }^{\mathrm{a} N}$.D.: Not detected.

TABLE 2: Concentration of components present in B100 biodiesel determined by gas chromatography.

\begin{tabular}{|c|c|c|c|}
\hline Peak & Retention time/min & Component & Concentration/\% (m/m) \\
\hline 1 & 10.6 & Free glycerin & 0.01 \\
\hline $2-6$ & $23.0-26.0$ & Methyl esters (C14 to C16) & $\begin{array}{c}21.74 \\
\text { (21.18 is methyl palmitate) }\end{array}$ \\
\hline $7-8$ & $27.6-28.4$ & $\begin{array}{l}\text { Mixture of methylic oleate, linoleate, } \\
\text { stearate and linolineate }\end{array}$ & $\begin{array}{c}73.34 \\
\text { (70.67 is methylic oleate and linoleate) }\end{array}$ \\
\hline $9-21$ & $>28.4-50.0$ & $\begin{array}{l}\text { High molar mass esters and partial } \\
\text { acylglycerols }\end{array}$ & 3.07 \\
\hline
\end{tabular}

The total and free glycerin contents in the biodiesel were $0.16 \%(\mathrm{~m} / \mathrm{m})$ and $0.01 \%(\mathrm{~m} / \mathrm{m})$, respectively, lower values than those limited by the Brazilian legislation that establishes maximum $0.25 \%(\mathrm{~m} / \mathrm{m})$ total glycerin and $0.02 \%(\mathrm{~m} / \mathrm{m})$ free glycerin [35].

The biodiesel presented flash point of $150.4^{\circ} \mathrm{C}$, specific mass of $890 \mathrm{~kg} \mathrm{~m}^{-3}$, at $20^{\circ} \mathrm{C}$, acidity index $0.19 \mathrm{mg} \mathrm{KOH} \mathrm{g}^{-1}$ and no methanol (Table 1); these parameters are in agreement with resolution 14 [35]. The Induction Period at $110^{\circ} \mathrm{C}$ for the B100 biodiesel sample, without the presence of antioxidants, was $3.56 \mathrm{~h}$ and was out of specifications established by the same resolution that establishes a minimum value of six hours.

The infrared spectroscopy (IR) technique was used to characterize the antioxidants. Figures 2(a), 2(b), and 2(c) show the spectra of the rosemary, oregano, and basil ethanolic extracts, respectively.

The first absorption band, shown in the three spectra (Figures 2(a), 2(b), and 2(c)), is in the $3300 \mathrm{~cm}^{-1}$ region and represents a vibration characteristic of alcohols and phenols. The interpretation of the spectra confirmed the presence of phenol compounds in the three extracts. As observed in the $2800 \mathrm{~cm}^{-1}$ region, a band was observed that could represent the $\mathrm{C}-\mathrm{H}$ aromatic bond. In $1750 \mathrm{~cm}^{-1}$ aromatic overtones were found. In addition, two bands were observed in the region of $1000-1260 \mathrm{~cm}^{-1}$ that might be alkene vibrations or C-O axial deformation of alcohol or phenol. At $1420-1330 \mathrm{~cm}^{-1}$ there was coupling with symmetric angular deformation vibrations outside the plane $\mathrm{C}-\mathrm{H}$ and angular deformation in the plane, characteristic of the $\mathrm{OH}$ grouping that determines primary and secondary alcohols.

Figure 2(b) shows that there was a relatively intense band only in the rosemary spectrum, in the $1600 \mathrm{~cm}^{-1}$ region, suggesting the possible presence of a $\mathrm{C}=\mathrm{O}$ group. In the rosemary spectrum the band attributed to $\mathrm{OH}$ group did not present its characteristic format, and seemed overlay with another band, at $2800 \mathrm{~cm}^{-1}$. Furthermore, although the main bands were common in the three spectra presented, the rosemary alcoholic extract spectra bands were slightly displaced, perhaps because of the strong interaction among the compounds present in the extract, that caused some spectral interference. However, by using the IR technique it was possible to attribute possible compounds present in the extract and above all, confirmed the presence of phenolic compounds, which was the main interest in the present characterization [38].

To assess the oxidative stability or susceptibility to oxidation, B100 biodiesel in mixed to alcoholic extracts of antioxidant spices was submitted to the accelerated stove method [21, 39]. 


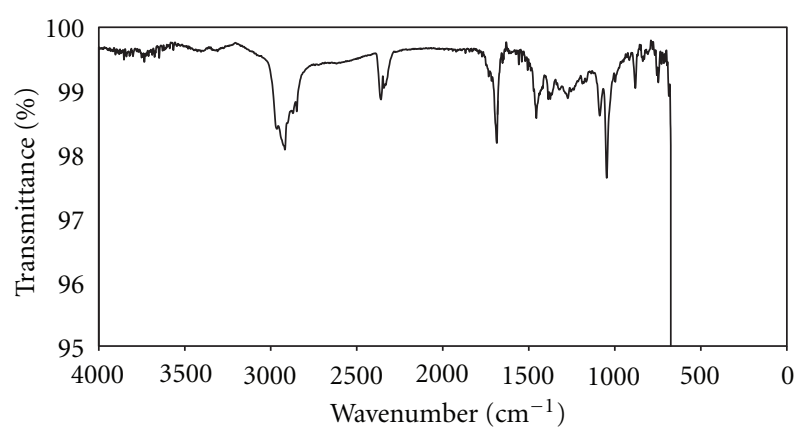

(a)

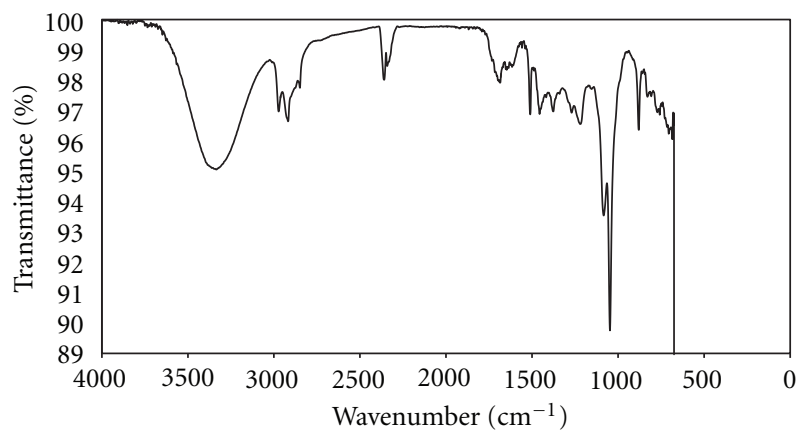

(b)

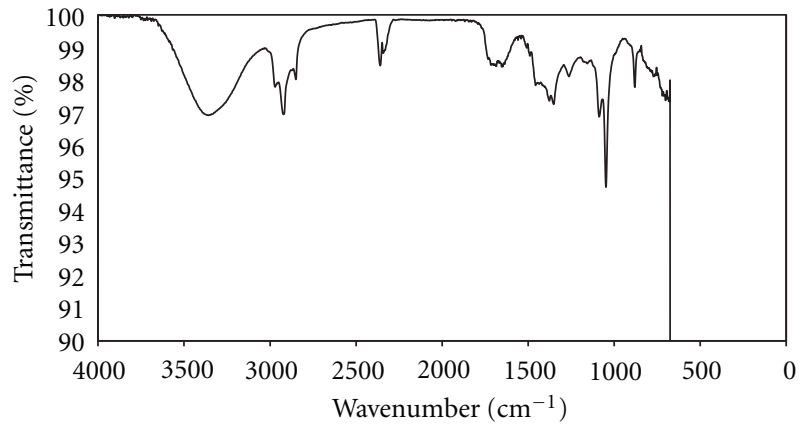

(c)

FIGURE 2: Infrared spectra recorded from alcoholic extracts of (a) rosemary, (b) oregano, and (c) basil.

The simplex-centroid mixture experimental design, consisting of seven trials with two replications at the central point (Table 3), was used to assess the effect of rosemary $\left(x_{1}\right)$, oregano $\left(x_{2}\right)$, and basil $\left(x_{3}\right)$ alcoholic extract addition into biodiesel.

Table 3 shows the influence of the natural antioxidants on the oxidative stability of the B100 biodiesel. The value of Induction Period decreased with increase in temperature and that most of the antioxidants delayed biodiesel oxidation compared to the control, except for treatments 2 and 3, at $70^{\circ} \mathrm{C}$, where the Induction Periods were similar than the control.

According to Frankel the accelerated stability methods have restricted validity because the oxidation mechanism changes as the sample is submitted to heating, light, or contact with metals, while tests carried out at room temperature are close to real storage. However, because they give quicker

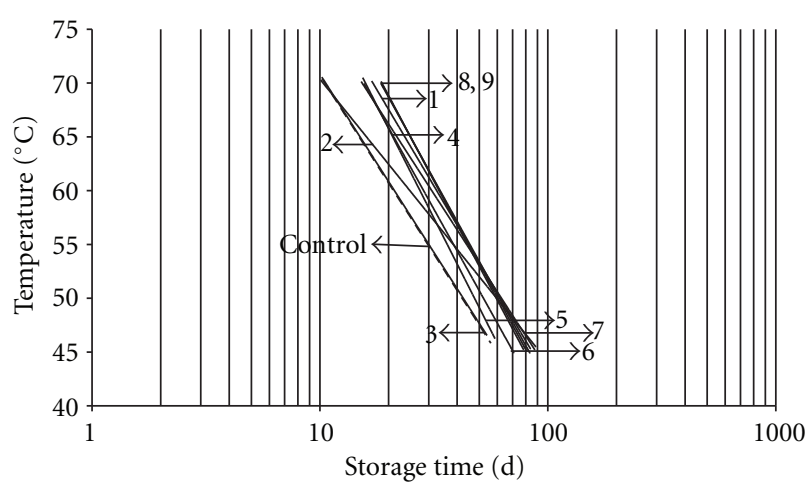

FIGURE 3: Relationship between natural logarithm of Induction Period (days) and the assay temperatures of biodiesel stabilized with natural antioxidants, and control sample, obtained by accelerated stove method.

TABLE 3: Induction period values (in days) obtained through stove accelerated method, according to simplex-centroid design of experiments.

\begin{tabular}{lcccc}
\hline \multirow{2}{*}{ Treatment } & \multirow{2}{*}{ Mixture $^{\mathrm{a}}$} & \multicolumn{3}{c}{ Induction period/d } \\
& $(1 ; 0 ; 0)$ & 84 & 46 & 17 \\
\hline 1 & $(0 ; 1 ; 0)$ & 88 & 41 & 10 \\
2 & $(0 ; 0 ; 1)$ & 54 & 35 & 10 \\
3 & $(1 / 2 ; 1 / 2 ; 0)$ & 88 & 45 & 15 \\
4 & $(1 / 2 ; 0 ; 1 / 2)$ & 59 & 40 & 15 \\
5 & $(0 ; 1 / 2 ; 1 / 2)$ & 71 & 38 & 16 \\
6 & $(1 / 3 ; 1 / 3 ; 1 / 3)$ & 78 & 46 & 19 \\
7 & $(1 / 3 ; 1 / 3 ; 1 / 3)$ & 83 & 45 & 19 \\
8 & $(1 / 3 ; 1 / 3 ; 1 / 3)$ & 81 & 45 & 19 \\
9 & - & 56 & 32 & 10 \\
Control & \multicolumn{4}{c}{ (\% rosemary; \% oregano; \% basil). }
\end{tabular}

results, the accelerated methods reduce work time and reagent consumption [40].

Figure 3 illustrates the resulting straight lines from alignment between the natural logarithm of the three IP of each treatment versus the three trial temperatures set out for the oxidative stability assessment of B100 biodiesel stabilized with natural antioxidants (and the control sample). High coefficient of determination values were observed $\left(R^{2}>\right.$ 0.98) in all the straight lines represented.

Straight line overlays were observed in the case of treatments 8 and 9 (central point replications) suggesting low dispersion data. It also happened to treatment 3 (100\% basil) and the control; this phenomenon can be observed as the Induction Period values of treatment 3 were very close to those of the control, as shown in Table 3.

Hasenhuettl and Wan [41] also reported high linear correlation between the natural logarithm of the Induction Period in function of temperature when they studied the oxidative stability of six different types of vegetable oils without using antioxidants. Xin et al. [42] observed the same performance when they studied stability in sunflower oil 
TABLE 4: Storage time $\left(25^{\circ} \mathrm{C}\right)$, in days, obtained according to simplex-centroid design of experiments.

\begin{tabular}{|c|c|c|c|c|}
\hline Treatment & Mixture $^{\mathrm{a}}$ & Storage time/d & Equation $^{\mathrm{b}}$ & $R^{2}$ \\
\hline 1 & $(1 ; 0 ; 0)$ & 310 & $T=-15.52 \ln [\mathrm{ST}]+114.04$ & 0.9987 \\
\hline 2 & $(0 ; 1 ; 0)$ & 535 & $T=-11.4 \ln [\mathrm{ST}]+96.62$ & 0.9969 \\
\hline 3 & $(0 ; 0 ; 1)$ & 242 & $T=-14.39 \ln [\mathrm{ST}]+103.96$ & 0.9776 \\
\hline 4 & $(1 / 2 ; 1 / 2 ; 0)$ & 363 & $T=-14.21 \ln [\mathrm{ST}]+108.77$ & 0.9993 \\
\hline 5 & $(1 / 2 ; 0 ; 1 / 2)$ & 189 & $T=-18.15 \ln [\mathrm{ST}]+120.14$ & 0.9846 \\
\hline 6 & $(0 ; 1 / 2 ; 1 / 2)$ & 237 & $T=-16.53 \ln [\mathrm{ST}]+115.39$ & 1 \\
\hline 7 & $(1 / 3 ; 1 / 3 ; 1 / 3)$ & 252 & $T=-17.31 \ln [\mathrm{ST}]+120.70$ & 0.9991 \\
\hline 8 & $(1 / 3 ; 1 / 3 ; 1 / 3)$ & 276 & $T=-16.65 \ln [\mathrm{ST}]+118.56$ & 0.9999 \\
\hline 9 & $(1 / 3 ; 1 / 3 ; 1 / 3)$ & 263 & $T=-16.98 \ln [\mathrm{ST}]+119.62$ & 0.9999 \\
\hline Control & - & 239 & $T=-14.41 \ln [\mathrm{ST}]+103.89$ & 0.9926 \\
\hline
\end{tabular}

${ }^{\mathrm{a}}\left(\%\right.$ rosemary; \% oregano; $\%$ basil); ${ }^{\mathrm{b}}\left(\mathrm{T}\right.$ : temperature, ${ }^{\circ} \mathrm{C} ;[\mathrm{ST}]$ : storage Time, d).

TABLE 5: Analysis of variance for storage time determined by stove accelerated method.

\begin{tabular}{lccccc}
\hline & F.D. & S.S. & M.S. & $F_{\text {calc }}$ & $F_{\text {tab }}$ \\
\hline Model & 6 & 82992.24 & 13832.04 & 96.92492 & 19.33 \\
Error & 2 & 285.42 & 142.71 & - & - \\
\hline Total & 8 & 83277.66 & - & - & - \\
\hline
\end{tabular}

TABLE 6: Induction period values (in days) obtained through Rancimat method, according to simplex-centroid design of experiments.

\begin{tabular}{lccccc}
\hline \multirow{2}{*}{ Treatment } & \multirow{2}{*}{ Mixture $^{\mathrm{a}}$} & \multicolumn{4}{c}{ Induction period/d } \\
& & $110^{\circ} \mathrm{C}$ & $115^{\circ} \mathrm{C}$ & $120^{\circ} \mathrm{C}$ & $130^{\circ} \mathrm{C}$ \\
\hline 1 & $(1 ; 0 ; 0)$ & 0.75 & 0.50 & 0.29 & 0.17 \\
2 & $(0 ; 1 ; 0)$ & 0.67 & 0.56 & 0.40 & 0.21 \\
3 & $(0 ; 0 ; 1)$ & 0.78 & 0.48 & 0.35 & 0.18 \\
4 & $(1 / 2 ; 1 / 2 ; 0)$ & 0.82 & 0.57 & 0.38 & 0.20 \\
5 & $(1 / 2 ; 0 ; 1 / 2)$ & 0.69 & 0.49 & 0.36 & 0.18 \\
6 & $(0 ; 1 / 2 ; 1 / 2)$ & 0.79 & 0.49 & 0.34 & 0.19 \\
7 & $(1 / 3 ; 1 / 3 ; 1 / 3)$ & 0.61 & 0.54 & 0.38 & 0.16 \\
8 & $(1 / 3 ; 1 / 3 ; 1 / 3)$ & 0.63 & 0.50 & 0.37 & 0.16 \\
9 & $(1 / 3 ; 1 / 3 ; 1 / 3)$ & 0.62 & 0.55 & 0.37 & 0.16 \\
Control & - & 0.15 & 0.09 & 0.07 & 0.03 \\
\hline
\end{tabular}

a $\%$ rosemary; $\%$ oregano; $\%$ basil).

biodiesel containing different concentrations of the propyl gallate antioxidant.

The Induction Periods at $25^{\circ} \mathrm{C}$ can be generated by extrapolation from the straight line equations, thus, the Storage Time (Table 4).

Therefore, it was observed that the trials containing natural antioxidant alcoholic extracts presented values greater than the $239 \mathrm{~d}$ observed for the control, except in treatments 5 and 6 , represented, respectively, by the binary mixture of rosemary and basil that presented a $189 \mathrm{~d}$ Storage Time, followed by the oregano and basil mixtures that resulted of $237 \mathrm{~d}$, a close value, but lower than the numerical value of the control sample. Among the other trials, the second treatment, containing $100 \%$ oregano extract, presented the highest Storage Time of $535 \mathrm{~d}$.
The canonic equation (3), fitted to the experimental data, where $Y_{\mathrm{ASM}}$ represents the Storage Time in days, according to the accelerated stove method, showed that the first, second, third, fifth, and sixth terms, with asterisk, were significant at the $5 \%$ level. One of these significant terms represented the rosemary and basil binary $\operatorname{mix}\left(x_{1} x_{3}\right)$ and the other represented the oregano and basil mix $\left(x_{2} x_{3}\right)$ and both presented negative coefficients, suggesting that these mixtures contributed negatively to the process, that is, they were not efficient for biodiesel protection:

$$
\begin{aligned}
Y_{\mathrm{ASM}}= & 310.17 x_{1}^{*}+535.20 x_{2}^{*} \\
& +241.57 x_{3}^{*}-237.66 x_{1} x_{2} \\
& -347.40 x_{1} x_{3}^{*}-605.38 x_{2} x_{3}^{*} \\
& +903.63 x_{1} x_{2} x_{3} .
\end{aligned}
$$

The coefficient of determination $\left(R^{2}\right)$ was greater than 0.99 indicating low dispersion of the experimental data. The model was significant at the level of 5\% (Table 5) and the lack of fit was not significant (10.39\%), indicating that the model can be considered suitable for prediction purposes [43].

The region of ternary recombination among the $x_{1}, x_{2}$, and $x_{3}$ independent variables can be observed in the surface response depicted in Figure 4. The region of the mixture with highest Induction Period is located on one of the vertices of the simplex-centroid design that represents the component containing $100 \%$ oregano extract.

Figure 5 shows the optimization of the Storage Time by the predictive equation and that a 535-day Storage Time for biodiesel, at room temperature, can be attained if mixed with $100 \%$ oregano alcoholic extract.

B100 biodiesel oxidation stability in natural antioxidant mixture was also assessed by the Rancimat accelerated oxidation method, set out in EN 14112 [25].

Values of the Induction Periods, in days, obtained with the Rancimat method following the simplex-centroid design are presented in Table 6 .

The specifications established by the EN 14112 [25] indicate that a minimum Induction Period should be greater than six hours $(0.25 \mathrm{~d})$ at $110^{\circ} \mathrm{C}$. According to Table 6 , for this 
TABle 7: Storage time (at $25^{\circ} \mathrm{C}$ ), in days, obtained according to Rancimat method and simplex-centroid design of experiments.

\begin{tabular}{|c|c|c|c|c|}
\hline Treatment & Mixture $^{\mathrm{a}}$ & Storage time/d & Equation $^{\mathrm{b}}$ & $R^{2}$ \\
\hline 1 & $(1 ; 0 ; 0)$ & 483.33 & $T=-13.06 \ln [\mathrm{ST}]+105.72$ & 0.9808 \\
\hline 2 & $(0 ; 1 ; 0)$ & 127.29 & $T=-16.41 \ln [\mathrm{ST}]+104.53$ & 0.9896 \\
\hline 3 & $(0 ; 0 ; 1)$ & 361.94 & $T=-13.73 \ln [\mathrm{ST}]+105.89$ & 0.9936 \\
\hline 4 & $(1 / 2 ; 1 / 2 ; 0)$ & 326.40 & $T=-14.16 \ln [\mathrm{ST}]+106.96$ & 0.9963 \\
\hline 5 & $(1 / 2 ; 0 ; 1 / 2)$ & 190.22 & $T=-15.11 \ln [\mathrm{ST}]+104.30$ & 0.9997 \\
\hline 6 & $(0 ; 1 / 2 ; 1 / 2)$ & 275.68 & $T=-14.34 \ln [\mathrm{ST}]+105.58$ & 0.9828 \\
\hline 7 & $(1 / 3 ; 1 / 3 ; 1 / 3)$ & 366.14 & $T=-13.61 \ln [\mathrm{ST}]+105.34$ & 0.9621 \\
\hline 8 & $(1 / 3 ; 1 / 3 ; 1 / 3)$ & 304.82 & $T=-13.95 \ln [\mathrm{ST}]+104.79$ & 0.9826 \\
\hline 9 & $(1 / 3 ; 1 / 3 ; 1 / 3)$ & 387.61 & $T=-13.5 \ln [\mathrm{ST}]+105.46$ & 0.9653 \\
\hline Control & - & 66.04 & $T=-13.81 \ln [\mathrm{ST}]+82.87$ & 0.9829 \\
\hline
\end{tabular}

a (\%rosemary; \%oregano; \%basil); ${ }^{b}\left(T:\right.$ Temperature, ${ }^{\circ} \mathrm{C} ;[\mathrm{ST}]$ : Storage Time, d).

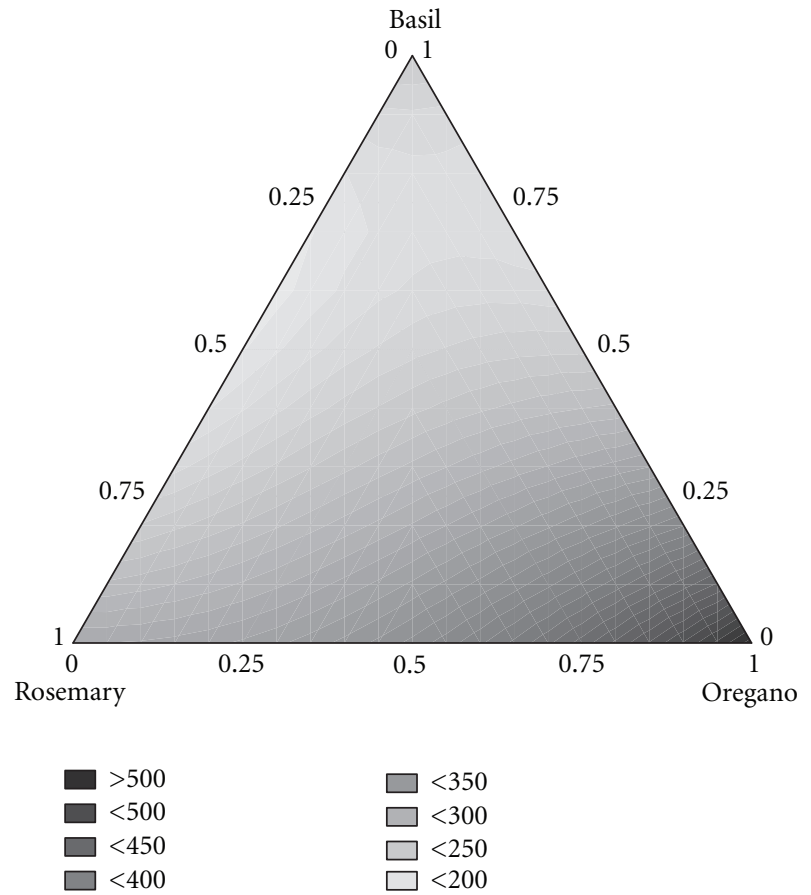

FIGURE 4: Response Surface for Storage Time determined by accelerated stove method.

temperature, all the treatments with antioxidants presented an Induction Period higher than the minimum established. Treatment 4, consisting of the binary rosemary and oregano mixture, resulted in the highest Induction Period $(0.82 \mathrm{~d})$, followed by treatment 6 , with $50 \%$ oregano and $50 \%$ basil with $0.79 \mathrm{~d}$ IP. Treatments 1 and 3 that correspond to the isolated components rosemary and basil, presented similar Induction Periods, 0.75 and $0.78 \mathrm{~d}$, respectively. The central point presented the lowest Induction Period, $0.62 \mathrm{~d}$, on average.

The $0.15 \mathrm{~d}$ Induction Period for the control at $110^{\circ} \mathrm{C}$ was shorter than the minimum established for this temperature, showing the importance of the antioxidants in B100 biodiesel conservation [35]. A similar value was obtained by Maia et al. [44] when studied the efficiency of synthetic antioxidants using B100 biodiesel from soybean oil. The IP values
TABLE 8: Analysis of variance for storage time determined by Rancimat method.

\begin{tabular}{lccccc}
\hline & F.D. & S.S. & M.S. & $F_{\text {calc }}$ & $F_{\text {tab }}$ \\
\hline Model & 6 & 89369.34 & 14894.89 & 8.069257 & 19.33 \\
Error & 2 & 3691.76 & 1845.88 & - & - \\
\hline Total & 8 & 93061.10 & - & - & - \\
\hline
\end{tabular}

obtained by Rancimat method, in this experiment using natural antioxidants, were higher than the ones observed by Maiaet al. [44] who tested synthetic antioxidants in biodiesel. These statements provide suitable comparison parameters emphasizing that natural antioxidants are as effective or more than synthetic ones, although it must be treated with aid owing to difference in concentration in the essays.

Figure 6 shows the temperatures in function of the natural logarithm of the Induction Periods for B100 biodiesel from soybean oil stabilized with the natural antioxidant mixtures and the control. All the straight lines illustrated presented coefficient of determination $\left(R^{2}\right)$ greater than 0.96 .

As carried out in the experiments by the accelerated stove method, the data were extrapolated to obtain Induction Periods at $25^{\circ} \mathrm{C}$ (Storage Time). All the samples containing antioxidants (Table 7 ) presented values greater than the $66.04 \mathrm{~d}$ observed for the control.

Equation (4) was obtained, where $Y_{R}$ represents the Storage Time, in days, according to Rancimat method, and the significant terms at the level of $5 \%$ are marked with asterisks:

$$
\begin{aligned}
Y_{R}= & 483.33 x_{1}^{*}+127.29 x_{2} \\
& +361.94 x_{3}^{*}+228.36 x_{1} x_{2}-929.66 x_{1} x_{3}^{*} \\
& +124.26 x_{2} x_{3}+2505.21 x_{1} x_{2} x_{3} .
\end{aligned}
$$

Although the analysis of variance (Table 8 ) has shown that the model was not significant at the level of $5 \%$, the $R^{2}$ value of 0.96 and $15.87 \%$ nonsignificant lack of fit allow the model to be used for predictive purposes.

Figure 7 presents the optimum region that corresponded to the vertex occupied by rosemary (with its component at 

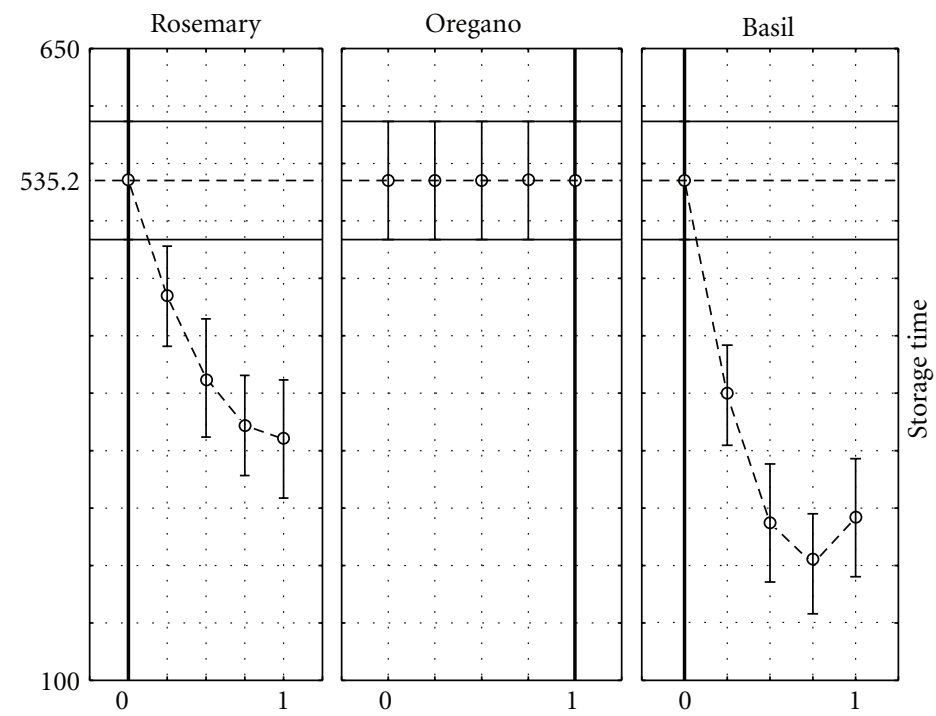

FIGURE 5: Optimum conditions profile for studied variables according to accelerated stove method.

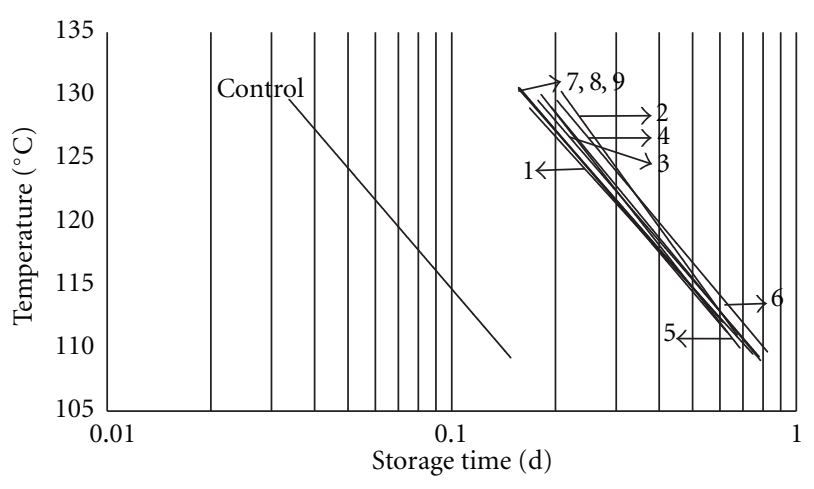

FIGURE 6: Relationship between natural logarithm of Induction Period (days) and the assay temperatures of biodiesel stabilized with natural antioxidants, and control sample, obtained by Rancimat method.

$100 \%)$ unlike that observed in the accelerated stove method, which presented the best mixture with $100 \%$ oregano extract.

Figure 8 shows optimization of Storage Time by the predictive equation. The estimated value of the Storage Time for biodiesel was $483.33 \mathrm{~d}$ and the optimum mixture consists of $100 \%$ of rosemary extract.

3.1. Combined Mathematical Model. The predicted response for a determined formulation can vary according to the complexity and variations during the process. Cornell and Deng [18] developed a proposal that combined the variables of the mixture components with the process variables, explaining that the influence of the process conditions can be observed on the mixture performance [45].
Equation (5) combines the discrete variables (or process variables) $z$, codified as $z=+1$ for the accelerated stove method and $z=-1$ for the Rancimat method:

$$
\begin{aligned}
Y= & 396.75 x_{1}^{*}+331.25 x_{2}^{*}+301.76 x_{3}^{*} \\
& -86.58 x_{1} z+203.96 x_{2} z-60.19 x_{3} z \\
& -76.65 x_{1} x_{2}-638.53 x_{1} x_{3}-240.56 x_{2} x_{3} \\
& -161.01 x_{1} x_{2} z+291.13 x_{1} x_{3} z^{*}-364.82 x_{2} x_{3} z^{*} \\
& +1921.37 x_{1} x_{2} x_{3}-1017.20 x_{1} x_{2} x_{3} z .
\end{aligned}
$$

When the $t$ test for the parameters containing the process variable was applied, it was found that three linear terms, the binary interaction terms between rosemary and oregano and basil and oregano and basil extracts, were significant at $5 \%$. Each one of the first three significant terms represented the components with 100\% rosemary, oregano, and basil without the effect combined with the $z$ variable.

When the optimized values of the Storage Times were applied to the joint equation (represented in Figures 5 and 8) the same values were obtained, that is, $535.20 \mathrm{~d}$ for B100 biodiesel with oregano extract using the accelerated stove method $(z=+1)$ to determine the Induction Period and 483.33 days using the rosemary extract with the Rancimat method $(z=-1)$ showing that the equation that included the process variable can be used for predictive purposes.

\section{Conclusions}

Applying the accelerated stove method indicated that biodiesel in a mixture with $100 \%$ oregano can present a shelf 


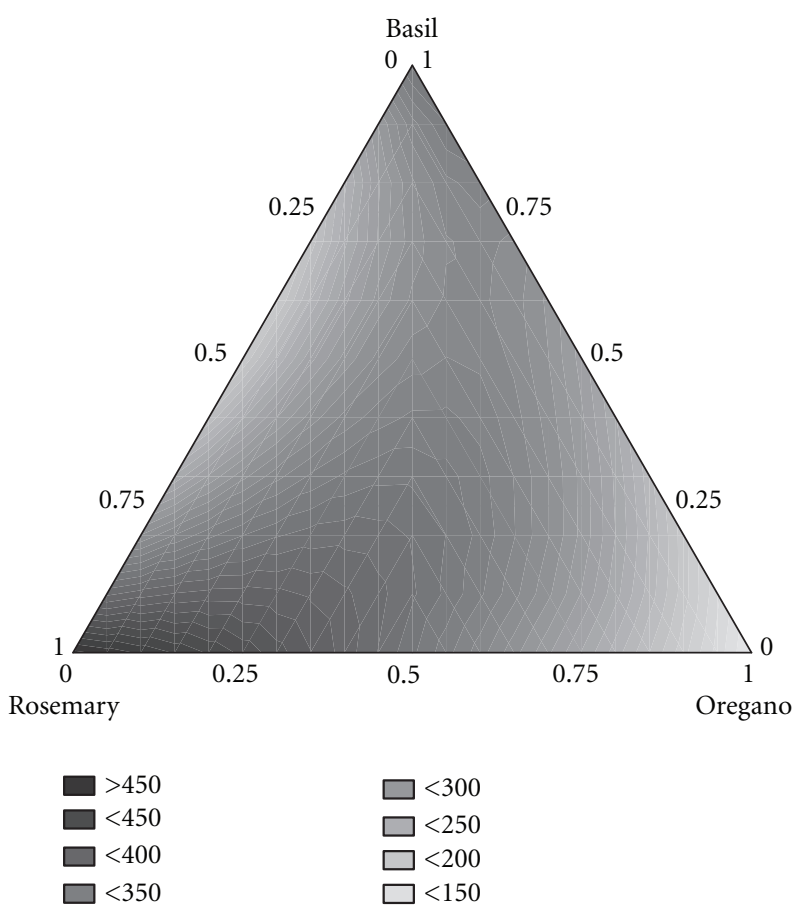

Figure 7: Response Surface for Storage Time determined by Rancimat method.
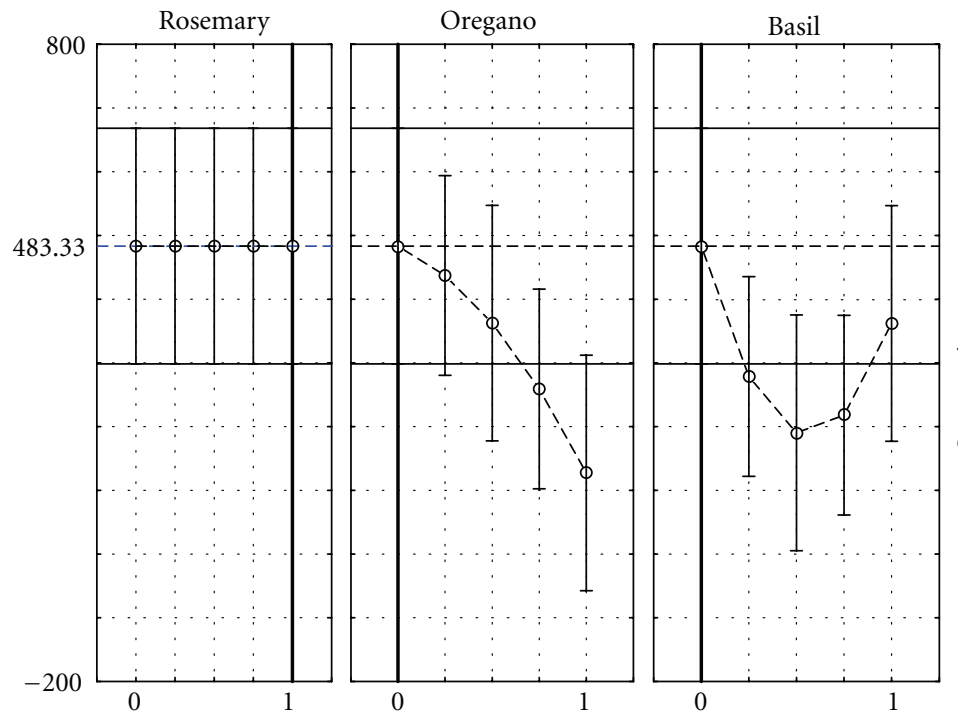

FIGURE 8: Optimum conditions profile for variables according to Rancimat method.

life of $535 \mathrm{~d}$ without showing evident oxidation. On the other hand, according to the Rancimat method, the ideal method consists of $100 \%$ rosemary, presenting $483 \mathrm{~d}$ storage. Nevertheless as the model constructed for the Rancimat method was not significant, it was considered that the accelerated stove method was the most suitable for the study in question. Furthermore, the trial temperatures were much closer to the ambient temperature that suggested a lower experimental error compared to the Rancimat method that worked with temperatures over $100^{\circ} \mathrm{C}$.
Finally, an antagonistic effect of basil when in binary mixture was observed in both methods used, suggesting that the alcohol extract of this seasoning does not present a satisfactory antioxidant effect.

\section{Acknowledgments}

The authors acknowledge State University of Londrina (UEL) and Mid-West State University (UNICENTRO) and acknowledge CAPES and CNPq for scholarships. 


\section{References}

[1] G. Knothe, "Some aspects of biodiesel oxidative stability," Fuel Processing Technology, vol. 88, no. 7, pp. 669-677, 2007.

[2] L. P. Ramos, K. T. Kucek, A. K. Domingos, and H. M. Wilhelm, "Um projeto de sustentabilidade econômica e sócio-ambiental para o Brasil," Revista Biotecnologia Ciência \& Desenvolvimento, pp. 28-37, 2003.

[3] R. A. Ferrari, V. S. Oliveira, and A. Escabio, "Biodiesel de soja-taxa de conversão em ésteres etílicos, caracterização físico-química e consumo em gerador de energia," Química Nova, vol. 28, pp. 9-23, 2005.

[4] L. C. Meher, D. V. Sagar, and S. N. Naik, "Technical aspects of biodiesel production by transesterification-a review," Renewable and Sustainable Energy Reviews, vol. 10, no. 3, pp. 248-268, 2006.

[5] R. A. Ferrari and W. L. De Souza, "Evaluation of oxidation stability of sunflower oil biodiesel with antioxidants," Quimica Nova, vol. 32, no. 1, pp. 106-111, 2009.

[6] V. C. Ramalho and N. Jorge, "Antioxidants used in oils, fats and fatty foods," Quimica Nova, vol. 29, no. 4, pp. 755-760, 2006.

[7] R. L. McCormick, M. Ratcliff, L. Moens, and R. Lawrence, "Several factors affecting the stability of biodiesel in standard accelerated tests," Fuel Processing Technology, vol. 88, no. 7, pp. 651-657, 2007.

[8] J. Pokorny, "Are natural antioxidants better- and safer- than synthetic antioxidants?" European Journal of Lipid Science and Technology, vol. 109, pp. 629-642, 2007.

[9] R. Amarowicz and R. B. Pegg, "Legumes as a source of natural antioxidants," European Journal of Lipid Science and Technology, vol. 110, no. 10, pp. 865-878, 2008.

[10] H. L. Madsen and G. Bertelsen, "Spices as antioxidants," Trends in Food Science and Technology, vol. 6, no. 8, pp. 271-277, 1995.

[11] N. Nakatani and R. Inatani, "Two antioxidative diterpenes from rosemary (Rosrnarinus officinalis L.) and a revised structure for rosmanol," Agricultural and Biological Chemistry, vol. 48, pp. 2081-2085, 1984.

[12] H. Kikuzaki and N. Nakatani, "Structure of a new antioxidative phenolic acid from oregano (Origanum vulgare L.)," Agricultural and Biological Chemistry, vol. 53, pp. 519-524, 1989.

[13] N. Bragagnolo and L. R. B. Mariutti, "Revisão: antioxidantes naturais da família lamiaceae. Aplicação em Produtos Alimentícios," Brazilian Journal of Food Technology, vol. 10, pp. 96-103, 2007.

[14] D. R. Thompson, "Designing mixture experiments-a review," Transactions of the American Society of Agricultural Engineers, vol. 24, no. 4, pp. 1077-1086, 1981.

[15] D. M. Steinberg and W. G. Hunter, "Experimental design: review and comment," Technometrics, vol. 26, no. 2, pp. 71-130, 1984.

[16] P. K. Soares, R. E. Bruns, and I. S. Scarminio, "Statistical mixture design investigation of fractionated and total extracts from Erythrina speciosaAndrews leaves," Journal of Separation Science, vol. 32, pp. 644-652, 2009.

[17] J. Marchi, J. C. Bressiani, A. H. A. Bressiani, and R. E. Bruns, "Mixture design and response surface analysis of densification of silicon carbide ceramics with $\left(\mathrm{SiO}_{2}-\mathrm{Dy}_{2} \mathrm{O}_{3}-\mathrm{Al}_{2} \mathrm{O}_{3}\right)$ additives," International Journal of Applied Ceramic Technology, vol. 7, no. 4, pp. 493-501, 2010.

[18] J. A. Cornell and J. C. Deng, "Combining process variables and ingredient components in mixing experiments," Journal of Food Science, vol. 47, pp. 836-843, 1982.
[19] D. C. Montgomery, "Experimental design for product and process design and development," The Statistician, vol. 44, part 2, pp. 159-177, 1999.

[20] M. C. Gacula, Design and Analysis of Sensory Optimization, Food \& Nutrition Press, Trumbull, Conn, USA, 1993.

[21] D. Borsato, C. L. B. Guedes, I. Moreira, J. P. Pinto, G. H. Dias, and K. R. Spacino, "Conditions optimization for obtaining biodiesel from soybean oil using the mixture experimental design," Semina, vol. 31, pp. 3-13, 2010.

[22] R. F. Almeida-Doria and M.A.B.. Regitano-D’Arce, "Antioxidant activity of rosemary and oregano ethanol extracts in soybean oil under thermal oxidation," Ciência E Tecnologia de Alimentos, vol. 20, pp. 197-203, 2000.

[23] American Oil Chemist's Society (A.O.C.S.), Official Methods and Recommended Practices of the American Oil Chemists Society, Champaign, Ill, USA, 5th edition, 1998.

[24] Y. H. Chen and Y. M. Luo, "Oxidation stability of biodiesel derived from free fatty acids associated with kinetics of antioxidants," Fuel Processing Technology, vol. 92, no. 7, pp. 1387-1393, 2011.

[25] Fat and Oil Derivatives-Fatty Acid Methyl Esters (FAME), "Determination of oxidation stability (accelerated oxidation test)," EN 14112:2003, European Committee for Standardization, Berlin, Germany, 2003.

[26] "Standard test method for density, relative density, and API gravity of liquids by digital density meter," ASTM D4052-09, ASTM International, 2002.

[27] "Standard test methods for flash point by Pensky-Martens closed cup tester," ASTM D93-10a, ASTM International, 2001.

[28] "Standard test method for acid number of petroleum products by potentiometric titration," ASTM D664-11, ASTM International, 2001.

[29] "Standard test method for determination of total monoglyceride, total diglyceride, total triglyceride, and free and total glycerin in B-100 biodiesel methyl esters by gas chromatography," ASTM D6584-10ae1, ASTM International, 2003.

[30] Fat and oil derivatives-Fatty Acid Methyl Esters (FAME), "Determination of ester and linolenic acid methyl esters content," EN 14103:2003, 2003.

[31] STATISTICA for Windows Software. v. 9. 0, Tulsa, OK, USA, 2009.

[32] V. Calado and D. C. Montgomery, Planejamento De Experimentos Usando O Statistica, E-Papers Serviços Editoriais, Rio de Janeiro, Brazil, 2003.

[33] J. A. Cornell, Experiments With Mixtures-Designs, Models and the Analysis of Mixture Data, John Wiley and Sons, New York, NY, USA, 2002.

[34] I. P. Lobo, S. L. C. Ferreira, and R. S. D. Cruz, "Biodiesel: quality parameters and analytical methods," Quimica Nova, vol. 32, no. 6, pp. 1596-1608, 2009.

[35] Brasil. Resolução n 14, de 11 de maio de 2012 da ANP, Agência Nacional do Petróleo, Gás Natural e Biocombustíveis.Estabelece a especificação para a comercialização de biodiesel que poderá ser adicionado ao óleo diesel. Diário Oficial da União, Brasília, 18 de maio de 2012.

[36] F. Karaosmanoglu and U. G. Becker, "Used oil as a fuel oil alternative," Energy Source, vol. 18, pp. 637-644, 1996.

[37] D. Borsato, L. H. Dall'antonia, C. L. B. Guedes et al., "The simplex-centroid design applied to study of the kinetics of the oxidation of B100 biodiesel in blend with synthetic antioxidants," Quimica Nova, vol. 33, no. 8, pp. 1726-1731, 2010. 
[38] R. M. Silverstein and F. X. Webster, IDentificaçao Espectrométrica De Compostos Orgânicos, LTC:, Rio de Janeiro, Brazil, 2000.

[39] E. N. Frankel, "In search of better methods to evaluate natural antioxidants and oxidative stability in food lipids," Trends in Food Science and Technology, vol. 4, no. 7, pp. 220-225, 1993.

[40] E. N. J. Frankel, "Review. Recent advances in lipid oxidation," Journal of the Science of Food and Agriculture, vol. 54, pp. 495-511, 1991.

[41] G. L. Hasenhuettl and P. J. Wan, "Temperature effects on the determination of oxidative stability with the metrohm rancimat," Journal of the American Oil Chemists Society, vol. 69, no. 6, pp. 525-527, 1992.

[42] J. Xin, H. Imahara, and S. Saka, "Kinetics on the oxidation of biodiesel stabilized with antioxidant," Fuel, vol. 88, no. 2, pp. 282-286, 2009.

[43] S. Mali, R. A. S. Silva, M. V. E. Grossmann, R. S. F. Silva, and D. Borsato, "Optimization of the production of acetylated distarch adipates using the novel software 'MULTIPLEX"' International Journal of Food Science and Technology, vol. 36, no. 6, pp. 641-647, 2001.

[44] E. C. R. Maia, D. Borsato, I. Moreira, K. R. Spacino, P. R. P. Rodrigues, and A. L. Gallina, "Study of the biodiesel B100 oxidative stability in mixture with antioxidants," Fuel Processing Technology, vol. 92, no. 9, pp. 1750-1755, 2011.

[45] K. M. Lee and D. F. Gilmore, "Formulation and process modeling of biopolymer (polyhydroxyalkanoates: PHAs) production from industrial wastes by novel crossed experimental design," Process Biochemistry, vol. 40, no. 1, pp. 229-246, 2005. 


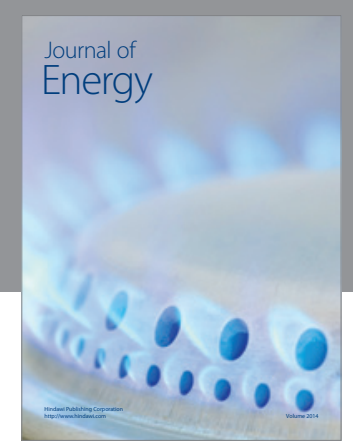

Journal of

Industrial Engineering
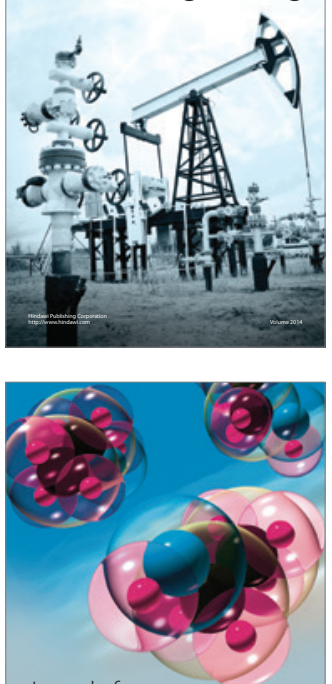

Fuels
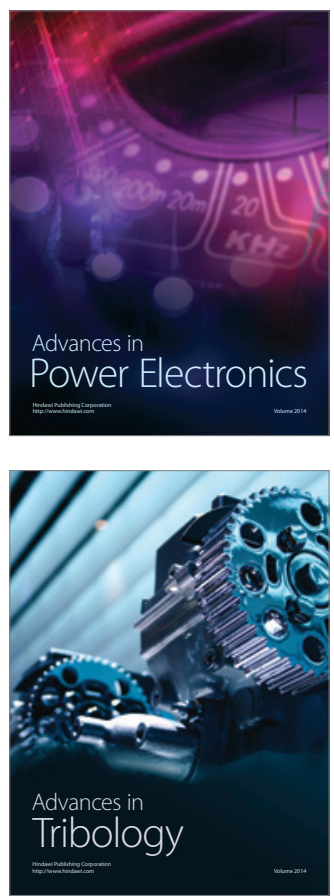

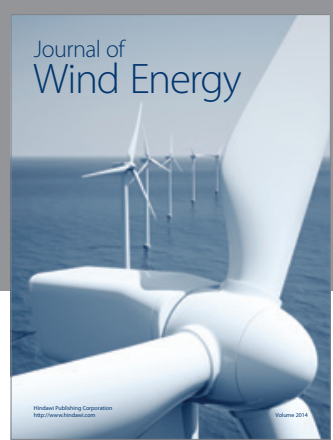

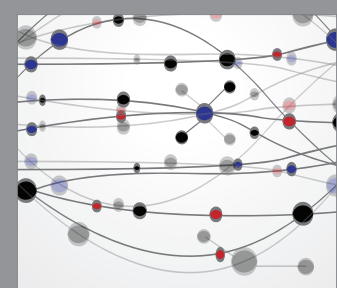

The Scientific World Journal

Submit your manuscripts at http://www.hindawi.com

Journal of

Structures
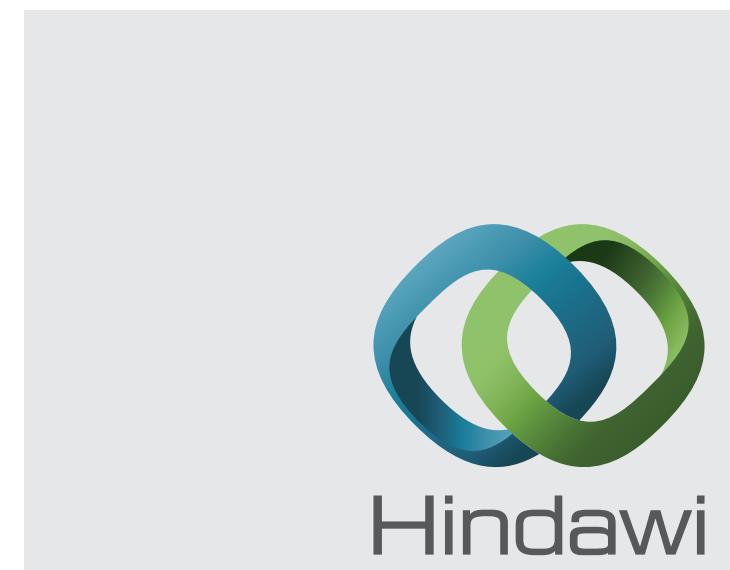

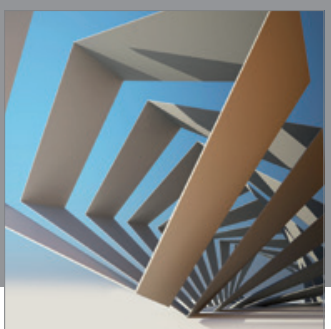

Rotating

Machinery
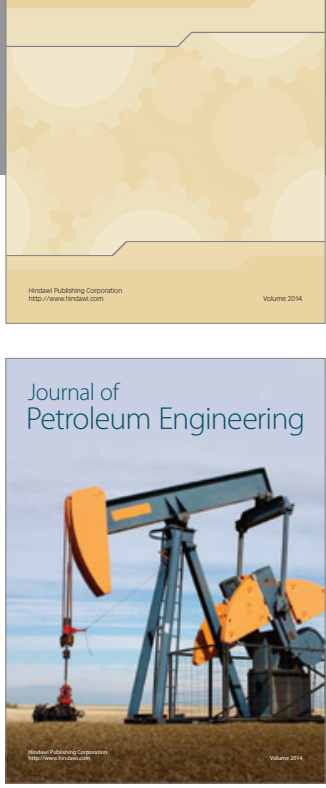

Journal of

Solar Energy
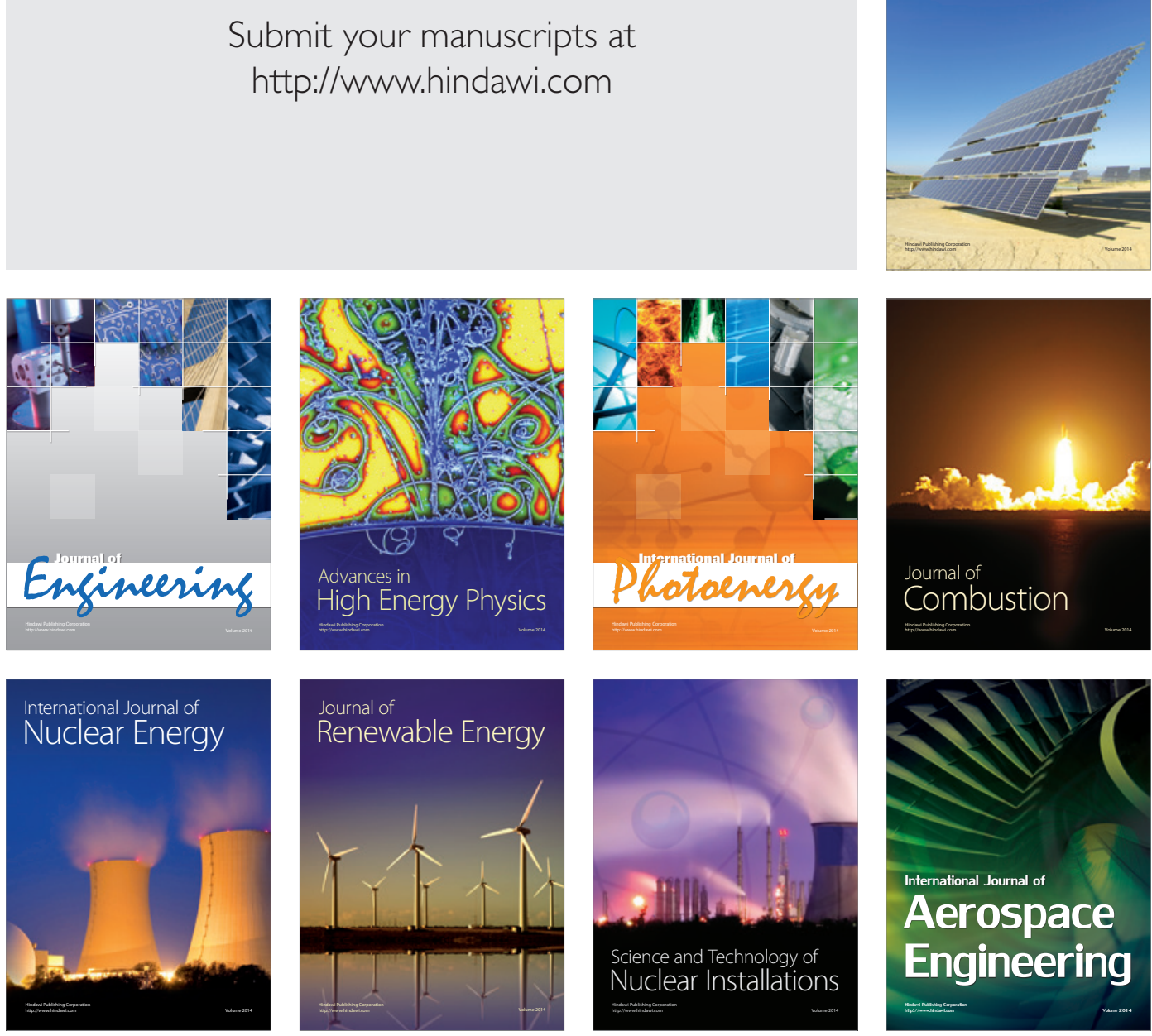